\title{
Problems in Translating Fictions
}

\author{
Dr. Kumar Rishikesh \\ National Institute of Technology \\ Patna, Bihar, India \\ krkesh@gmail.com
}

\begin{abstract}
The present paper tries to look into the socio-linguistic challenges and barriers concerned with translation of literary prose as prose constitutes ideologies, cultural values, as well as social, political, psychological and philosophical world views which always remain anthropocentric. Comparison of the original titles of the Hindi stories of Premchand and its translation as well as the interpretative role of the translator have been critically evaluated to establish the fact that a successful translator apart from mapping location, identities and cultural conflicts of the source language and the target language must be equally aware of the desire images of the writer to be translated
\end{abstract}

Keywords: Translation- Socio-linguistics- Culture- Images etc.

In the past two or three decades, developments in the fields of transformational grammar, general and contrastive linguistics, semantics, information theory, anthropology, semiotics, psychology and discourse analysis have exerted a great influence on general translation theory. They have enabled the discipline to broaden the areas of investigation and to offer fresh insights into the concept of correspondence on transference between linguistic and cultural systems. These new perspectives on theoretical front and inter-lingual contrastive analysis have contributed much to the understanding and mastering of the nature and skill of 
translation. But lamenting thing is that the translation of literary prose has still benefitted very little. It is still not taken seriously and encouraged.

In literary translations, still greater attention is being given to poetry and drama rather than to literary prose like fictions, short stories, essays and novellas. Unfortunately, translations of prose fiction as a literary genre have remained most neglected. It is also thought to be an easy process.

But in reality, the translation of fiction remains much more conflicted than the translation of other genres as it deals not only with bilingual but also bi-cultural and bi-social transference. It includes the entire complex of emotions, associations and ideas. Its language doesn't remain divided according to principles of rhymes, rhythm, meter or word-patterning. Unlike drama it is written to be read rather than acted or performed. Moreover, events are described or dramatized. It can take many different forms like satirical, autobiographical, gothic and scientific. Translation of literature poses a good deal of problems for the translator. Literature translation involves not only the transference of meaning but a host of associations charged with the meaning which need to be translated from Source Language (SL) text into Target Language (TL) text. Since the basic loss of meaning is one a continuum between under translation and over translation, it becomes necessary and imperative to divide literary translation genre wise. No doubt among the translation of poetry, drama and prose, to translate poetry remains the most difficult task because of the complex nature of poetry. For instance Savory writes that poetry is:

"The art of employing words in such a manner as to produce an illusion on the senses; the art of doing by means of words what the painter does by means of colours. Poetry, then, produces an illusion; it acquires memorableness by certain features which can be more easily recognized than reproduced at will. There is rhythm, metrical rhythm; there is emotion, sensuous emotion; there is an increased use of figures of speech and 
a degree of disregard for conventional word order; there is imagination and above all, there is an ability to see features in an object or a situation which another, not a poet might miss.”(Savory: 1959: 75).

Thus, poems are read chiefly for their aesthetic value. Every poem records an experience of the author and the translator, who gets aesthetic satisfaction by reading it, tries to re-enact the original experience of the author. Therefore Lila Ray says that the problem of language and equivalence is not easy to overcome in poetry. She writes that:

"Unless the original experience is recreated, no form, however perfect, can be anything but lifeless. The translator has to enter into the mind and heart of his author, relive his circumstances, re-feel what he felt, re-perceive what he perceived." (Lakshmi: 1993 : 79).

A similar view is laid down by Paul Selver in The Art of Translating Poetry in which he mentions the specific problematic areas which a translator encounters while the process of translation. He lists the main ingredients of poems like the subject matter, rhythmic structure, and verbal effects as well as features like musical qualities and subtleties of style to be the most challenging problems. He writes that:

"As regards verbal melody, it is obvious that, when a poem is transmuted from one language to another, its actual sounds, including such musical effects as they produce, must almost inevitably undergo radical changes. What emerges will, more often than not, be different, admirable perhaps, but different." (Selver:1966: 22:).

Thus, the translation of poetry involves far greater difficulties than that of any other genre of literature. It is by no means an easy task to translate a poem effectively without sacrificing any of the ingredients present in the original. It is very difficult to capture the spirit, style and atmosphere of the original. The meaning of the original poem can be rendered into the target language faithfully. But in poetry form and content are inseparable to 
each other. Formal requirements determine and modify content to a far wider extent than in everyday speech. In poetry, the transmission of information is secondary to the manner of presentation and the content itself is defined and limited by the formal organization of the message. In fact, poems are being appreciated more for their quality, style, metre, rhymes and figures of speech than for their meaning. In poetry, as in every literary text, words not only carry their plain meanings but also carry connotative, stylistic and cultural meanings. These distinctive features pose great problem for the translators. Bijay Kumar Das is right to say that:

The translator of poetry should remember that he is to 'translate' a piece of poetry, not to 'rewrite' or 'produce an interpretation' of it." (Das: 2009:48)

P. S. Deshpande also has a similar view when he says that:

"Poetry, being a highly developed form of human communication, a translator has first to catch subtleties, the packed allusive turn, the unexpressed suggestive and the thing ineffable and devise ways and means of transferring these in the new language. Besides these things he must also carry ever the spirit of a poem, the characteristic power of its expression and the turn of its rhythmical movement from SL to RL." (Deshpande: 1984:45-46)

Unlike the studies involved in the problems of translating poetry, a little importance has been given on the study of the translation of dramatic texts. There is very little material on the special problems of translating dramatic texts, and the statements of individual theatre translators often imply that the methodology used in the translation process is the same as that used to approach prose texts. In no aspect can a dramatic text be translated in the same way as the prose text. A theatre text is read differently. It is read as something incomplete because the full potential of the text is realized only in performance. This poses a most challenging problem for the translator; whether to translate the text as a purely literary text or 
to try to translate it in its function as one element in another. Anne Ubersfeld rightly illustrates that a dramatic text exhibits its full meaning only in its performance. She writes that:

"The task of the director, therefore, is to 'translate' into another language, a text of which he has a prime duty to remain 'faithful'. This position is based on the concept of semantic equivalence between the written text and its performance, only the 'mode of expression' in the Hjelmslevian sense of the term will be altered, the form and the content of the expression will remain identical when transferred from a system of test signs to a system of performance signs.” (Das:2009:49).

The translation of prose especially of the novels is equally difficult and problematic. The central problem for the translation of prose is the difficulty of determining translation units. A text is a prime unit which has dialectical relationship with other texts and is located within a specific historical context. On the other hand the translator of poetry can more easily break the prime text down into translatable units e.g. lines, verses and stanzas.

No doubt a novel can be broken down into chapters or sections, the structuring of a prose text by no means remains as linear as the chapter divisions seem to indicate. Therefore the translator has to consider the function both of the text and of the devices within the text itself. Every prime text is made up of a series of interlocking systems, each of which has a determinable function in relation to the whole and it is the task of a translator to apprehend these functions. For instance, if a translator takes each sentence or paragraph as a minimum unit and translated it without relating to the overall work, the translated text will have the paraphrasable content of the passage at the cost of everything else. Therefore, the translator of prose has to consider the prose text as a structures whole while bearing in mind the stylistic and syntactical exigencies of the target language. 
Therefore, it can be said that literary prose consists of a much greater social and linguistic influence than the other two literary genres. Translation of literary prose involves the exchange of the social experience of individual in the specific world with readers in another culture and society. The following table having the translations of the titles of an eminent twentieth century short story and fiction writer, Munsi Premchand not only offers an incomparable panorama of North-Indian life, and a devastating satire on the cruelty and pride of the privileged class, but also reflects the special problems associated with the text in translating with, satire, humour, history, myth and social realism:

\begin{tabular}{|l|l|}
\hline Hindi Titles of the Short Stories & English translations of the titles. \\
\hline Mukti-Marg & The Road to Salvation \\
\hline Babaji Ka Bhog & A Feast for the Holy Man \\
\hline Garib Ki Hay & The Power of a Curse \\
\hline Vidhvans & A Catastrophe \\
\hline Pus ki Raat & January Night \\
\hline Neyur & Neyur \\
\hline Thakur Ka Kuan & The Thakur's well \\
\hline Tagada & A Day in the Life of a Debt \\
\hline Satyagrah & Collector \\
\hline Manushya Ka Param Dharm & A moral Victory \\
\hline Guru-Mantra & Man's Highest Duty \\
\hline Chakma & A Lesson in the Holy Life \\
\hline Zurmana & A Little Trick \\
\hline & Penalty \\
\hline
\end{tabular}




\begin{tabular}{|l|l|}
\hline Kaayar & A Coward \\
\hline Narak Ka Maarg & The Road to Hell \\
\hline Bade Bahi Sahab & My Big Brother \\
\hline Nasha & Intoxication \\
\hline Dudh Kam Daam & The Price of Milk \\
\hline Kafan & The Shroud \\
\hline
\end{tabular}

(Rubin: 1971: Content)

The translated titles give a clear picture of those problems which remain associated in translating a Hindi prose text especially of Premchand's who has a very wide field of dispersion. For instance the simplicity and naturalness of the style are deep-rooted in Indian culture and consciousness. They have come out as a challenge for David Pupin. For instance, the translation of the tilte 'Babaji Ka Bhog' into A Feast for the Holy Man fails to bring out the humour and irony associated with it. Moreover, we can say that one peculiar feature of Premchand's vocabulary is that when he finds the existing vocabulary of the Hindi language or the language concerned inadequate to express his meanings, he used to coin new words. This situation operates with Premchand on two levels. At first, when there is some English word in his mind for which no Hindi equivalent is available. For instance

\begin{tabular}{|l|l|}
\hline Hindi Paraphrase & Word in English \\
\hline Patra Kagaz & Letter Paper \\
\hline Mulaquati Card & Visiting Card \\
\hline Jebi Lantern & Torch \\
\hline Taapmapak & Thermometer \\
\hline
\end{tabular}

Secondly when he finds a pressure of his creative style. For instance, in Hindi, there is no word like 'levata' but Premchand coins it to meet the demand of his style: 
“ Purus ke paas stri ko dene ke liye kya hai? Wah devata nahi levata hai. ( Godan 162)[Hindi Sentence]

"Man has nothing to give to woman. He is not a giver but a receiver." (English equivalent)

Here, it is seen that no justice has been done with the style of Premchand in this translation. In Hindi, the word 'Devata' means 'God' but here Premchand is using it in two different ways. Firstly like a God and secondly, it refers to giver 'Devata' from the Hindi root word 'de' which means 'to give'. In order to stress the selfish tendency of man as compared to woman, Premchand has coined this word 'Levata' from the Hindi root word 'le' which means 'to take' and thus successfully establishes several points through a small sentence. The most beautiful aspect of this style lies in the fact that 'levata' has been coined on the analogy of 'devata' and both of them are being used in one sentence and highlights man's tendency to take and not to give.

Sometimes allusion to subjects also comes out to be a big problem for the translator which becomes immediately clear to an Indian reader, but it requires special explanation to anyone from another culture.

Hence it can be said that translation of literary prose, especially short stories and novels depends largely on various factors, including aesthetic conventions, historical and cultural social circumstances, writer's individualism and the writer's world view, among which reproduction of the prose style is regarded as its core. It raises certain issues of relationship between the writer and the subject, the writer and his audience and the translator and the text. The translator of a creative literary text should have insight into the way the author of a literary work employs language to his own ends, i.e., he should employ specific textual and discoursed strategies so that he can get his communicative objectives. He should set certain conditions or parameters to get translation equivalence like lexical meaning, structure, 
texture, sentence meaning, utterance meaning, presuppositions, style, cognition and literary effect.

These parameters of components can become helpful to a translator to get translation equivalents too. However, the behavior of language in the exchange of messages and in the establishment of interpersonal relations remain so complicated and delicate that any minor textual variation can be attributed to variation in the discourse value or in the shades of meaning. There is an additional difficulty in literary translation too. Since it employs various types of figuration, phonological, syntactic and semantic patterns, some translators find difficulty in establishing equivalents in TL.

In this condition, one must take socio-semiotic approach into consideration so that various aspects of the philological, linguistic, communicative and ideological factors associated with the source text can be understood and transferred into the target language text. Nida too has advocated to follow socio-semiotic approach in the process of translation:

"Perhaps the most pervasive and crucial contribution to understanding the translation process is to be found in socio-semiotics, the discipline that treats all systems of sign used by human societies. The great advantage of semiotics over other approaches to inter-lingual communication is that it deals with all types of signs and codes, especially with language as the most comprehensive and complex of all systems of signs employed by humans. No hostile approach to translating can exclude semiotics as a fundamental discipline in encoding and decoding signs". (Nida, 1993).

In short, socio-semiotic approach helps one understand better not only the meanings of words, sentences and discourse structures but also the symbolic nature of distinguishing between designative and associative meanings. The same can be affirmed with the general 
approach that a translator should not work with general percepts. They should work with an eye on each individual structure whether it is a prose or a verse. 


\section{References}

Belloc, Hilaire, On Translation. Oxford, The Claredon Press 1931.

Bogatyrev Peter, 'Les Signes des theatre', Poetique, VIII, 1971.

Das B.K. A Handbook of Translation studies, New Delhi. Atlantic Publishers and Distributors Private 2009.

Despande P.S. "Translating Poetry and Scriptural Texts: Theory and Practice" in Essays on comparative Literature and Linguistics, New Delhi. Sterling Publishers Pvt. Ltd. 1984.

Rubin David (Tr.). The World of Premchand: Selected Stories of Premchand. Indiana University Press, Bloomington and London: 1971

Devy, G.N. In Another Tongue, Madras, Macmillian: 1993.

Devy G.N. "Translation Theory: An Indian Perspective", Translation from Periphery to Centrestage. New Delhi. Prestige Books: 1998.

George Steiner. After Babel: Aspects of language and Translation. London.Oxford University Press:1975.

Kalyani P.K. Translation Studies. New Delhi Creative Books: 2001.

Mukherjee. S. 'Translation as New Writing' Cygnus 2:2 (1981)

Mukerjee Sujit. Translation as Diccovery. Orient Longman New Delhi.

Savory Theodre. The Art of Translation. London. Jonathan Cape: 1959.

Selver Paul. The Art of Translating Poetry. London. Job Baker: 1966.

Ubersfild Anne. Lire le Theatre Paris Sociales: 1978.

Veltrusky Jiri. Drama as Literature. Lisse. Peter de Pidder Prees: 1977 